\title{
Performances in cerebellar and neuromuscular transmission tests are correlated in migraine with aura
}

\author{
Anna Ambrosini · Peter S. Sándor · \\ Victor De Pasqua $\cdot$ Francesco Pierelli • \\ Jean Schoenen
}

Received: 2 October 2007 / Accepted: 24 November 2007/Published online: 5 February 2008

(C) Springer-Verlag 2008

\begin{abstract}
In previous studies, we described subclinical abnormalities of neuromuscular transmission and cerebellar functions in migraineurs. The aim of this study was to search if these two functions are correlated in the same patient. Thirteen migraineurs [five without aura (MO) and eight with aura (MA)] underwent both stimulation-SFEMG and 3D-movement analysis. Single fiber EMG (SFEMG) results were expressed as the "mean value of consecutive differences" (mean MCD). Precision of arm-reaching movements (measured with an infrared optoelectronic tracking system) was expressed as the average deviation in the horizontal plane. Median values of mean MCD and mean horizontal deviation were not different between MO and MA. However, in MA, but not in MO, both variables were positively correlated. Thus, we conclude that neuromuscular transmission and cerebellar functions are correlated in the same patient when affected by migraine
\end{abstract}

\footnotetext{
A. Ambrosini $(\bowtie)$

Headache Clinic, IRCCS INM Neuromed, via Atinense 18,

86077 Pozzilli, Isernia, Italy

e-mail: anna.ambrosini@neuromed.it

P. S. Sándor

Headache and Pain Unit, Department of Neurology,

University of Zurich, Zurich, Switzerland

V. De Pasqua

Headache Research Unit, Department of Neurology,

University of Liège, Liège, Belgium

F. Pierelli

Department of Neurorehabilitation, University "La Sapienza"

of Rome, Polo Pontino, ICOT, Latina, Italy

J. Schoenen

Headache Research Unit, Departments of Neurology

and Neuroanatomy, University of Liège, Liège, Belgium
}

with aura. We suggest that this correlation might be due to a common molecular abnormality.

Keywords Migraine $\cdot$ Cerebellum $\cdot$ Neuromuscular junction $\cdot$ Genetics

\section{Introduction}

Migraine is a paroxysmal neurological disorder with a high prevalence in the general population. There is strong epidemiological and genetic evidence that genetic factors play a major, though variable role, in its pathogenesis. Migraine patients are characterized between attacks on various CNSevoked responses by a deficit of habituation $[1,2]$, which may have a familial character [3-5]. The lack of habituation may play a role in migraine pathogenesis [6]. By contrast, other mild abnormalities have been identified that are unlikely to play a pathogenic role: a decreased safety factor at the neuromuscular junction on single fiber EMG (SFEMG) [7-9] and subclinical cerebellar hypermetria in the horizontal plane on opto-electronic analysis of upper arm-reaching movements [10]. It was suggested that these two abnormalities might reflect the same underlying genetic abnormality. If this is correct, one may expect that in the same individual they be of a similar degree. We have therefore compared in the same migraine patient the SFEMG and 3D-movement analysis.

\section{Materials and methods}

Patients

Thirteen migraine patients (ICHD-II) [11] were recruited from the Headache Clinic of the Headache Research Unit 
in Liège, Belgium. Eight patients suffering from typical aura with migraine headache (MTA-ICHD-II code 1.2.1; three women and five men; median age 28.5 years; range 13-67) and five patients with migraine without aura (MO-ICHD-II code 1.1; three women and two men; median age 40.0 years; range 31-51) underwent both stimulation-SFEMG and 3D-movement analysis. All patients were right-handed. None of them had any other medical condition detectable by history and clinical examination; none was taking drugs on a regular basis, nor had taken any drug within 3 days before the recordings. The recordings took place at least 3 days after and before an attack (checked by telephone-interview).

The study was conducted after approval of our Institution's ethics committee and performed in accordance with the ethical standards of the 1964 Declaration of Helsinki, with the understanding and consent of each involved subject.

\section{SFEMG recordings}

A Nicolet Viking IV device (Nicolet ${ }^{\circledR}$ Biomedical, Madison, Wisconsin, USA) was used for stimulation single fiber electromyography [12]. Single muscle fiber activity was recorded with 25-mm-long single fiber needles (Medelec Neurodiagnostic Accessories, ref: 16829, Witney, Oxfordshire, UK), and the motor nerve was stimulated with Nicolet teflon-insulated monopolar needles. We stimulated suprathreshold the motor branch of the radial nerve and assessed the variability in latency, i.e. the jitter (Fig. 1), of single fiber action potentials in $\mathrm{m}$. extensor digitorum communis (EDC) of the right arm. Stimulations-acquisitions were 100 per muscle fiber, and stimulation rate was $10 \mathrm{~Hz}$. We recorded $25 \mathrm{EDC}$ muscle fibers per patient. Offline analyses of recordings were performed, and on average 18 artifact-free EDC muscle fibers per patient were selected to assess their mean MCD. Results were expressed as the "mean value of consecutive differences" (MCD) of successive interpotential intervals, as usual in SFEMG studies.

\section{D-movement analysis}

Movements were recorded at $100 \mathrm{~Hz}$ in three dimensions (3D) using an infrared optoelectronic-tracking-system (ELITE $^{\mathrm{TM}}$, Milan, Italy) with a reflective marker attached to the tip of the index finger and another marker to the movement target.

Participants were seated with the target in the mediosagittal plane on eye level. They were instructed to start with the right arm extended to the right, to touch the target

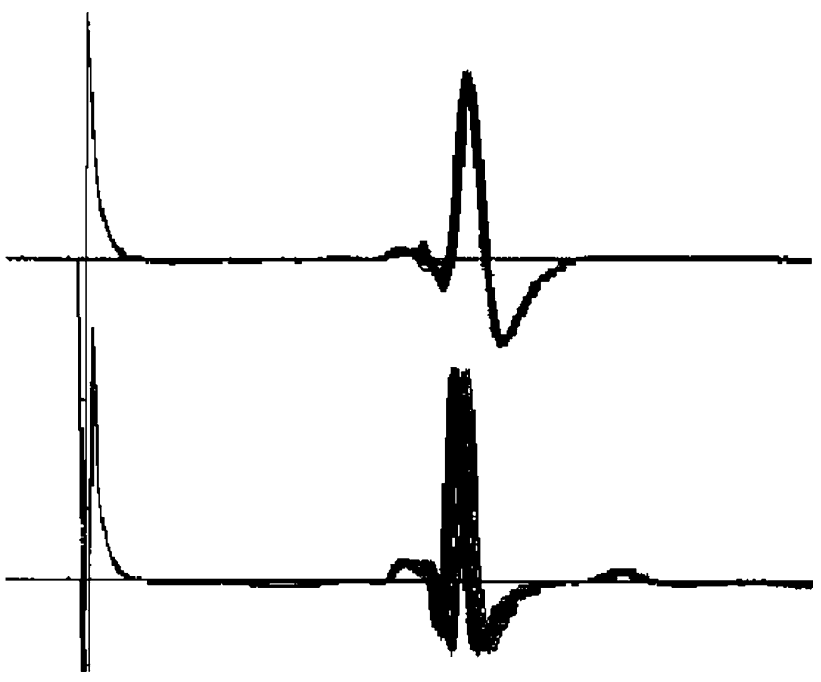

Fig. 1 Figures representing a normally (on the top) and an abnormally (on the bottom) jittered fibers

with high precision (but fast) without any trunk movement, to go back to the starting position and to repeat above movements, in a given pace over $15 \mathrm{~s}$ (one trial) to result in 8-10 movements (Fig. 2). The used Cartesian coordinate system is head-fixed with a nasooccipital, a horizontal and a vertical axis and the origin in the target. Since in our previous study [10] abnormalities in migraineurs were most pronounced in the horizontal plane, we limited ourselves to an analysis of the mean deviation in the horizontal plane (in millimeters), measured over four trials, each consisting of 8-10 arm movements.

Quantitative variables in each group of migraine patients (MO and MTA) were expressed as medians. Differences between groups were analysed with the Mann-Whitney $U$ test. The Spearman rank order correlation test was used to compare the values of the mean MCD on SFEMG and the mean horizontal deviation on 3D-movement analysis.

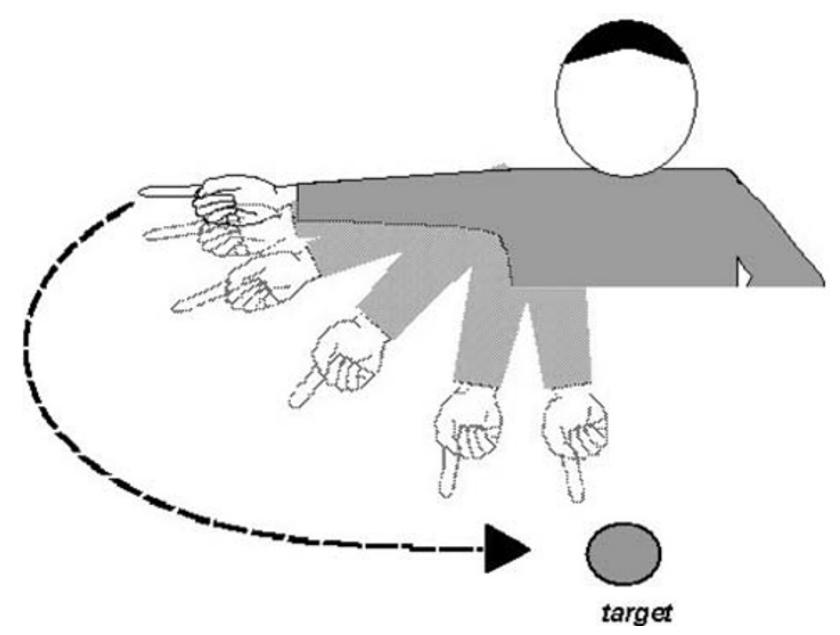

Fig. 2 Experimental setup for the movement task 


\section{Results}

On SFEMG, the median value for mean MCD was not significantly different between MO $(16.05 \mu \mathrm{s}$; range 9.50 22.93) and MTA (18.91 $\mu \mathrm{s}$; range 11.50-24.55). The median value of mean horizontal deviation was $4.01 \mathrm{~mm}$ (range -3.25 to 18.12 ) in $\mathrm{MO}$ and $10.74 \mathrm{~mm}$ (range 1.6017.03) in MTA, a nonsignificant difference.

In $\mathrm{MO}$, there was no significant correlation between mean MCD and mean horizontal deviation. By contrast, in MTA, both variables were positively correlated $(R=0.71$, $P=0.046$ ) (Fig. 3).

\section{Discussion}

Our within-patient analysis shows that, in migraine with aura, the mean MCD on SFEMG increases significantly with the degree of horizontal deviation in a visually guided reaching movement. This suggests that, in subgroups of migraine patients, neuromuscular transmission (NMT) performance and control of ballistic movements by the lateral cerebellum are similarly influenced by a common biochemical and/or neural mechanism.

Although no gene mutations have been identified till now, the genetic load is thought to be higher in the pathogenesis of migraine with aura than that without aura [13]. In familial hemiplegic migraine 1 (FHM1) [14], mutations have been found in the CACNA1A gene, which codifies for the main subunit of P/Q-type $\mathrm{Ca}^{2+}$ channels, heavily concentrated at the neuromuscular junction and in the cerebellum [15-18]. Thus, we initially hypothesized that the NMJ and cerebellar abnormalities found in some migraine patients might be due to dysfunctioning $\mathrm{Ca}^{++}$

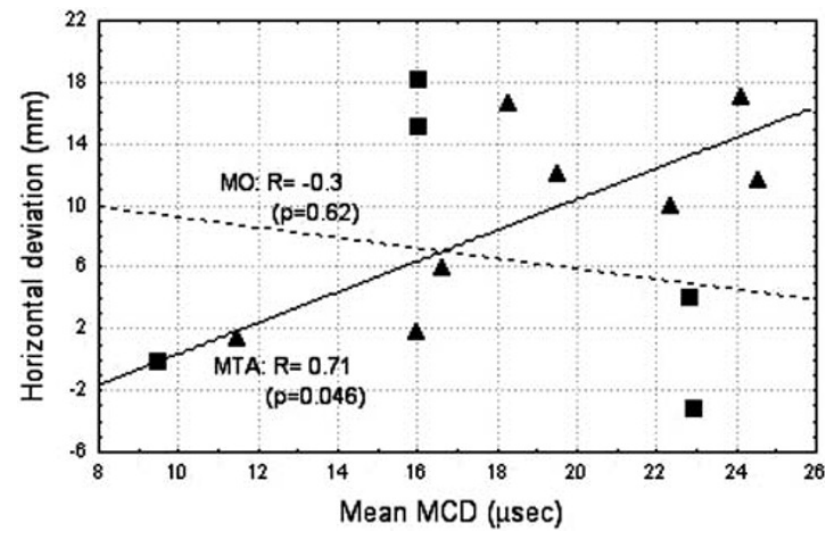

Fig. 3 Scatter plot relating mean MCD on SFEMG ( $X$ axis, $\mu \mathrm{s})$ and mean horizontal deviation on $3 \mathrm{D}$ analysis of a reaching arm movement ( $\mathrm{Y}$ axis, $\mathrm{mm}$ ), and linear regression lines. Migraine without aura patients (MO): squares, dashed line. Migraine with aura patients (MTA): triangles, continuous line channels. However, SFEMG studies were normal in FHM1 [19], and mutations in the CACNA1A gene are not found in patients suffering from the common forms of migraine, with or without aura [20]. Some evidence that the CACNA1A gene may be involved in migraine with typical aura [21], and the facts that NMT impairment can be found in episodic ataxia type 2, an allelic disorder of FHM1 [22], and normalizes after treatment with acetazolamide [23] are still in favor of a possible involvement of $\mathrm{Ca}^{++}$channels, particularly in migraine with aura.

Other proteins implicated in migraine pathophysiology may constitute a common link between neuromuscular junctions (NMJ) and the cerebellum. This is unlikely for the alpha-2 subunit of the Na-K ATPase, of which the gene ATP1A2 is mutated in FHM2 [24], because the alpha-2 isoform is found at intracellular membranes [25] and not at the NMJ, where the major role is played by the alpha-3 isoform [26]. Moreover, SFEMG results were found normal in FHM2 patients [19].

By contrast, a different group of calcium channels, the R-type, influence neuromuscular transmission and can compensate for dysfunctioning P/Q channels [27]. Moreover, they seem to play a role in cerebellar functions [28]; thus, their activity may influence in parallel NMJ and cerebellar performances, similarly to what we found in the subgroup of migraineurs with aura. The CACNA1E gene, which codes for the alpha-1E subunit of R-type channels, is precisely located on locus 1q31, for which significant linkage was found in the common forms of migraine [29], and a single nucleotide polymorphism was more frequent in subgroups of patients affected by migraine with aura [30].

In conclusion, the correlation between NMJ and cerebellar performances that we have found in migraine with aura patients might be due to a common genetically determined molecular mechanism, possibly influencing ion channels functions, but this has still to be proven by appropriate genetic studies.

Acknowledgments This study was supported by grant numbers 3.4523.00 and 3.4566.96 of the National Fund for Medical Research, Brussels (Belgium), by grant number 125 of the Migraine Trust, London (UK) and by a bilateral scientific cooperation project between Italy and the French Community of Belgium 2003-2004 and 20052006. A.A. is the recipient of the IHS-Pat Humphrey Research Fellowship 2002.

Conflict of interest None.

\section{References}

1. Schoenen J, Ambrosini A, Sandor PS, Maertens de Noordhout A (2003) Evoked potentials and transcranial magnetic stimulation in migraine: published data and viewpoint on their pathophysiologic significance. Clin Neurophysiol 114(6):955-972 
2. Ambrosini A, Schoenen J (2006) Electrophysiological response patterns of primary sensory cortices in migraine. $J$ Headache Pain 7(6):377-388

3. Sandor PS, Afra J, Proietti-Cecchini A, Albert A, Schoenen J (1999) Familial influences on cortical evoked potentials in migraine. Neuroreport 10(6):1235-1238

4. Siniatchkin M, Kropp P, Neumann M, Gerber W, Stephani U (2000) Intensity dependence of auditory evoked cortical potentials in migraine families. Pain 85(1/2):247-254

5. Di Clemente L, Coppola G, Magis D, Fumal A, De Pasqua V, Schoenen J (2005) Nociceptive blink reflex and visual evoked potential habituations are correlated in migraine. Headache 45(10):1388-1393

6. Schoenen J (1998) Cortical electrophysiology in migraine and possible pathogenetic implications. Clin Neurosci 5(1):10-17

7. Ambrosini A, de Noordhout AM, Alagona G, Dalpozzo F, Schoenen J (1999) Impairment of neuromuscular transmission in a subgroup of migraine patients. Neurosci Lett 276(3):201-203

8. Ambrosini A, Maertens de Noordhout A, Schoenen J (2001) Neuromuscular transmission in migraine: a single-fiber EMG study in clinical subgroups. Neurology 56(8):1038-1043

9. Domitrz I, Kostera-Pruszczyk A, Kwiecinski H (2005) A singlefibre EMG study of neuromuscular transmission in migraine patients. Cephalalgia 25(10):817-821

10. Sandor PS, Mascia A, Seidel L, de Pasqua V, Schoenen J (2001) Subclinical cerebellar impairment in the common types of migraine: a three-dimensional analysis of reaching movements. Ann Neurol 49(5):668-672

11. Headache Classification Subcommittee of the International Headache Society (2004) The international classification of headache disorders, 2nd edition. Cephalalgia 24(Suppl 1):1-160

12. Trontelj JV, Mihelin M, Fernandez JM, Stalberg E (1986) Axonal stimulation for end-plate jitter studies. J Neurol Neurosurg Psychiatry 49:677-685

13. Russell MB, Iselius L, Olesen J (1996) Migraine without aura and migraine with aura are inherited disorders. Cephalalgia 16(5):305-309

14. Ophoff RA, Terwindt GM, Vergouwe MN, van Eijk R, Oefner PJ, Hoffman SM, Lamerdin JE, Mohrenweiser HW, Bulman DE, Ferrari M, Haan J, Lindhout D, van Ommen GJ, Hofker MH, Ferrari MD, Frants RR (1996) Familial hemiplegic migraine and episodic ataxia type- 2 are caused by mutations in the $\mathrm{Ca} 2+$ channel gene CACNL1A4. Cell 87(3):543-552

15. Mori Y, Friedrich T, Kim MS, Mikami A, Nakai J, Ruth P, Bosse E, Hofmann F, Flockerzi V, Furuichi T et al (1991) Primary structure and functional expression from complementary DNA of a brain calcium channel. Nature 350(6317):398-402

16. Hillman D, Chen S, Aung TT, Cherksey B, Sugimori M, Llinas RR (1991) Localization of P-type calcium channels in the central nervous system. Proc Natl Acad Sci USA 88:7076-7080

17. Mintz IM, Adams ME, Bean BP (1992) P-type calcium channels in rat central and peripheral neurons. Neuron 9:85-95
18. Stea A, Tomlinson WJ, Soong TW, Bourinet E, Dubel SJ, Vincent SR, Snutch TP (1994) Localization and functional properties of a rat brain alpha $1 \mathrm{~A}$ calcium channel reflect similarities to neuronal Q- and P-type channels. Proc Natl Acad Sci USA 91:10576-10580

19. Terwindt GM, Kors EE, Vein AA, Ferrari MD, van Dijk JG (2004) Single-fiber EMG in familial hemiplegic migraine. Neurology 63(10):1942-1943

20. Jen JC, Kim GW, Dudding KA, Baloh RW (2004) No mutations in CACNA1A and ATP1A2 in probands with common types of migraine. Arch Neurol 61(6):926-928

21. Terwindt GM, Ophoff RA, van Eijk R, Vergouwe MN, Haan J, Frants RR, Sandkuijl LA, Ferrari MD; Dutch Migraine Genetics Research Group (2001) Involvement of the CACNA1A gene containing region on $19 \mathrm{p} 13$ in migraine with and without aura. Neurology 56(8):1028-1032

22. Jen J, Wan J, Graves M, Yu H, Mock AF, Coulin CJ, Kim G, Yue Q, Papazian DM, Baloh RW (2001) Loss-of-function EA2 mutations are associated with impaired neuromuscular transmission. Neurology 57(10):1843-1848

23. Ambrosini A, Pierelli F, Schoenen J (2003) Acetazolamide acts on neuromuscular transmission abnormalities found in some migraineurs. Cephalalgia 23(2):75-78

24. De Fusco M, Marconi R, Silvestri L, Atorino L, Rampoldi L, Morgante L, Ballabio A, Aridon P, Casari G (2003) Haploinsufficiency of ATP1A2 encoding the $\mathrm{Na}+\mathrm{K}+$ pump alpha2 subunit associated with familial hemiplegic migraine type 2 . Nat Genet 33:192-196

25. Hundal HS, Maxwell DL, Ahmed A, Darakhshan F, Mitsumoto Y, Klip A (1994) Subcellular distribution and immunocytochemical localization of $\mathrm{Na}, \mathrm{K}-\mathrm{ATPase}$ subunit isoforms in human skeletal muscle. Mol Membr Biol 11(4):255-262

26. Zahler R, Sun W, Ardito T, Zhang ZT, Kocsis JD, Kashgarian M (1996) The alpha3 isoform protein of the $\mathrm{Na}+\mathrm{K}(+)$-ATPase is associated with the sites of cardiac and neuromuscular impulse transmission. Circ Res 78(5):870-879

27. Kaja S, Van de Ven RC, Ferrari MD, Frants RR, Van den Maagdenberg AM, Plomp JJ (2006) Compensatory contribution of Cav2.3 channels to acetylcholine release at the neuromuscular junction of tottering mice. J Neurophysiol 95(4):2698-2704

28. Osanai M, Saegusa H, Kazuno AA, Nagayama S, Hu Q, Zong S, Murakoshi T, Tanabe T (2006) Altered cerebellar function in mice lacking CaV2.3 Ca2+ channel. Biochem Biophys Res Commun 344(3):920-925

29. Lea RA, Shepherd AG, Curtain RP, Nyholt DR, Quinlan S, Brimage PJ, Griffiths LR (2002) A typical migraine susceptibility region localizes to chromosome 1q31. Neurogenetics 4(1):17-22

30. Ambrosini A, D’Onofrio M, Grieco GS, Di Mambro A, Casali C, Montagna G, Colazza GB, Nicoletti F, Nappi G, Schoenen J, Buzzi MG, Santorelli FM, Pierelli F (2005) Single nucleotide polymorphisms on the CACNA1E gene in subtypes of migraine with aura. J Headache Pain 6:346-371 [Abstract] 